\title{
Survey of psychiatrist use of digital technology in clinical practice
}

\author{
Rita Bauer ${ }^{1}$,Tasha Glenn², Scott Monteith ${ }^{3}$, Peter C. Whybrow ${ }^{4}$ and Michael Bauer ${ }^{1 *}$ (D)
}

\begin{abstract}
Background: Psychiatrists were surveyed to obtain an overview of how they currently use technology in clinical practice, with a focus on psychiatrists who treat patients with bipolar disorder.

Methods: Data were obtained using an online-only survey containing 46 questions, completed by a convenience sample of 209 psychiatrists in 19 countries. Descriptive statistics, and analyses of linear associations and to remove country heterogeneity were calculated.

Results: Virtually all psychiatrists seek information online with many benefits, but some experience information overload. 75.2\% of psychiatrists use an EMR/EHR at work, and 64.6\% communicate with patients using a new technology, primarily email (48.8\%). 66.0\% do not ask patients if they use the Internet in relation to bipolar disorder. $67.3 \%$ of psychiatrists feel it is too early to tell if patient online information seeking about bipolar disorder is improving the quality of care. $66.3 \%$ of psychiatrists think technology-based treatments will improve the quality of care for some or many patients. However, $60.0 \%$ of psychiatrists do not recommend technology-based treatments to patients, and those who recommend select a variety of treatments. Psychiatrists use technology more frequently when the patients live in urban rather than rural or suburban areas. Only 23.9\% of psychiatrists have any formal training in technology.

Conclusions: Digital technology is routinely used by psychiatrists in clinical practice. There is near unanimous agreement about the benefits of psychiatrist online information-seeking, but research on information overload is needed. There is less agreement about the appropriate use of other clinical technologies, especially those involving patients. It is too early to tell if technology-based treatments or patient Internet activities will improve the quality of care. The digital divide remains between use of technology for psychiatrists with patients living in urban and rural or suburban areas. Psychiatrists need more formal training in technology to understand risks, benefits and limitations of clinical products.
\end{abstract}

\section{Background}

Digital technology is viewed as fundamental to achieving better care, better patient experience and lower costs (Berwick et al. 2008). Digital technology is also described as having the potential for transformative change in psychiatry in both service delivery and treatments (Bhugra et al. 2017). With the increasing emphasis and investment

\footnotetext{
*Correspondence: Michael.Bauer@uniklinikum-dresden.de

1 Department of Psychiatry and Psychotherapy, University Hospital Carl Gustav Carus Medical Faculty, Technische Universität Dresden, Dresden, Germany

Full list of author information is available at the end of the article
}

in technology for all aspects of clinical psychiatry, how psychiatrists perceive technology is critically important.

The objective of this study was to survey psychiatrists to obtain an overview of how they are currently using technology in clinical practice. The survey focused on psychiatrists that treat patients with bipolar disorder, as patients with bipolar disorder use the Internet with the same frequency as the general public, and over $3 / 4$ seek information on bipolar disorder online (Bauer et al. 2016; Conell et al. 2016). Additionally, new technology tools are often thought to be well suited for collecting and analyzing patient data from patients with bipolar disorder (Bauer et al. 2020; Monteith et al. 2016). This survey 
collected information on the types of products and communications routinely used in clinical practice, the products and websites routinely recommended to patients with bipolar disorder, the technical background of psychiatrists, and general attitudes towards the use of technology. As technology continues to rapidly change, and new products are regularly introduced that modify the practice of psychiatry, more understanding of the psychiatrist perspective is needed.

\section{Methodology}

\section{Survey}

An Internet based survey was created using LimeSurvey software Version 2.56.1 (LimeSurvey 2019), which could be completed from a Windows, Mac, or smartphone device using a web browser. The survey questions focused on 6 areas in addition to demographics: (1) physician communication with patients, (2) patient information seeking about bipolar disorder, (3) technology recommendations for patients, (4) physician information seeking, (5) technology use at work and (6) technology knowledge and attitudes. A small pilot study was completed in Dresden, and the survey questions were refined based on the feedback and results. The survey contained 46 questions and took on average $26.9 \mathrm{~min}$ to complete. The survey, and all associated correspondence, were in English. The survey questions along with the psychiatrists responses, except for demographics, are provided in Additional file 1.

\section{Survey recruitment}

Invitations to complete the survey were sent by email to a convenience sample of psychiatrists and others who regularly provide care to those with mental illness. The initial contacts were psychiatrists who participate in international groups related to bipolar disorder. Those who responded were then sent an email with a link and a unique access key to the survey. Those who responded but did not complete the survey were sent a reminder email after several weeks. In addition, 36 respondents provided at least 10 additional contacts. A total of 747 invitations were sent. There were no financial incentives for participating. Data were collected between June and November, 2017.

\section{Statistics}

Descriptive statistics were generated for all survey questions. Many categorical survey responses were summarized into two groups for analysis. For questions that required the respondent to choose one of many options, each option was assigned to a group. For questions that allowed the respondent to choose all options that apply, the respondent was assigned to a group if any options in the group were chosen. The Mantel-Haenszel Chi square test was used to assess association between two variables, such as the association of a response on the use of technology with a demographic variable across multiple strata or countries. Heterogeneity across countries was checked using the Breslow-Day test, and only results without heterogeneity between countries are reported. A $\mathrm{p}$ value of less than 0.05 was considered statistically significant. SPSS Version 25 was used to perform the statistical computations. As this was an exploratory survey, no adjustments were made for multiple comparisons.

\section{Results}

Of the 747 invitations sent, there were 281 completed surveys for a $37.6 \%$ response rate. Since 220 of the 281 respondents were psychiatrists, surveys from the small mix of other professions were excluded. Surveys from countries with less than 3 respondents were also excluded, leaving 209 completed surveys from psychiatrists in 19 countries for analysis. The demographic characteristics of the 209 psychiatrists are shown in Table 1 . The countries of the 209 psychiatrists are shown in Additional file 1 . In this sample, very few statistical differences were found that were due to differences between countries. The results listed below apply across all countries.

\section{Table 1 Demographics of the psychiatrists $(N=209)$}

\begin{tabular}{lrc}
\hline Demographic category & N & $\%$ \\
\hline Year of birth & 111 & 53.1 \\
Born before 1980 & 98 & 46.9 \\
Born 1980 or later & & \\
Gender & 128 & 61.2 \\
Male & 81 & 38.8 \\
Female & & \\
Year graduated from medical school & 100 & 48.3 \\
Graduated before 2005 & 107 & 51.7 \\
Graduated 2005 or later & & \\
Years practicing psychiatry & 102 & 48.8 \\
Practicing less than 15 years & 107 & 51.2 \\
Practicing 15 years or more & & \\
Type of Practice & 113 & 54.1 \\
Private practice, clinic or hospital & 96 & 45.9 \\
Academic hospital or primarily research & & \\
Type of Area Most Patients are From & 166 & 79.4 \\
Urban & \\
Suburban or rural & 43 & 20.6 \\
Percent of patients with mood disorder & & \\
More than 50\% & 132 & 63.2 \\
50\% or less & 77 & 36.8 \\
\hline
\end{tabular}




\section{Physician communication with patients}

The technology the psychiatrists use to routinely communicate with patients is shown in Table 2-Q11. Overall, $64.6 \%$ of psychiatrists communicate with patients using a new technology, primarily standard email (48.8\%). When their patients live in urban areas, compared to suburban or rural areas, psychiatrists are more likely to communicate by standard email ( $55 \%$ vs $26 \%, \mathrm{p}=0.004$ ) and by text message ( $40 \%$ vs $16 \%, \mathrm{p}=0.009)$. When their patients live in suburban or rural areas, psychiatrists are less likely to communicate using any new technologies (65\% vs $28 \%, \mathrm{p}<0.001)$. Psychiatrists vary in perspective on the appropriate uses of email or online communication with patients, as shown in Table 2-Q12. Psychiatrists are more likely to think email or online communication is appropriate for medication refills if they work in academic settings ( $45 \%$ vs. $27 \%, \mathrm{p}=0.022$ ), or their patients live in urban areas $(38 \%$ vs. $23 \%, \mathrm{p}=0.034)$. Psychiatrists are more likely to think that email or online communications is appropriate for routine clinical follow-ups if they have been practicing for at least 15 years (36\% vs. $17 \%, \mathrm{p}=0.011)$, or their patients live in urban areas $(30 \%$ vs. $12 \%, 0.018)$. Older psychiatrists, born before 1980 , are less likely to think email or online communication is appropriate for administrative issues $(62 \%$ vs. $78 \%$, $\mathrm{p}=0.010$ ). When patients have important clinical information, $33.0 \%$ of psychiatrists want patients to schedule an office visit, $28.7 \%$ to call the office phone, $18.2 \%$ call a personal cellphone, $12.0 \%$ email, and $6.7 \%$ send a text message.

\section{Patient information seeking-bipolar disorder}

Of the respondents, $66.0 \%$ do not ask patients if they use the Internet in relation to bipolar disorder. About 23.6\% of psychiatrists said at least half of patients with bipolar disorder discussed information found online, while $76.4 \%$ said less than half. When psychiatrists ask patients if they use the Internet in relation to bipolar disorder, it is more likely that at least half of patients discuss online findings ( $39 \%$ vs. $15 \%, \mathrm{p}=0.003)$. When patients discuss information about bipolar disorder found online with the psychiatrist, $86.6 \%$ discuss pharmaceutical treatments and side effects, $57.9 \%$ discuss the course of illness and symptoms, $57.9 \%$ alternative treatments, and $24.9 \%$ experiences at chat rooms and forums. Patients that live in urban areas are more likely to discuss information on the course of illness and symptoms ( $63 \%$ vs $40 \%, \mathrm{p}=0.021)$. Patients with bipolar disorder who discuss information found online are viewed as more informed by $64.4 \%$ of the psychiatrists, and especially when their patients live in urban areas ( $69 \%$ vs. $47 \%, \mathrm{p}=0.019)$. Psychiatrists who view patients that discuss online information as more informed are more likely to ask patients if they use the Internet in relation to bipolar disorder (77\% vs. $58 \%$; $\mathrm{p}=0.033$ ). The information patients found online about bipolar disorder is viewed as some accurate/some inaccurate by $75.6 \%$ of psychiatrists, generating unnecessary fears by $36.4 \%$, relevant by $28.2 \%$, mostly inaccurate by $12.0 \%$ and not related to the patient's diagnosis by $8.1 \%$. When patients discuss information found online, $46.9 \%$ of psychiatrists rarely or never review the website, while $53.1 \%$ routinely or occasionally review the website. About $42.6 \%$ of patients occasionally, and $44.5 \%$ rarely request a treatment for bipolar disorder found online. When psychiatrists ask patients if they use the Internet in relation to bipolar disorder, more patients request a treatment for bipolar disorder found online ( $63 \%$ vs $38 \%, \mathrm{p}=0.003$ ).

Of the psychiatrists, $86.6 \%$ feel there are positive consequences to patients searching online for information on bipolar disorder as shown in Table 2-Q22. Other consequences are shown in Table 2-Q21. Those working in academic settings are more likely to have increased patient requests for a diagnosis of bipolar disorder (41\% vs. $26 \%$, $\mathrm{p}=0.013$ ). Those with patients living in urban areas are more likely to have increased patient requests for unnecessary medications or tests ( $54 \%$ vs $32 \%, \mathrm{p}=0.048)$, and more likely see improved coping with the illness $(30 \%$ vs. $14 \%, p=0.040$ ). Of the psychiatrists, $21.2 \%$ feel that online information seeking is improving the quality of care, while $67.3 \%$ feel it is too early to tell. About half feel it is improving the doctor-patient relationship for some patients and $10.6 \%$ for many patients.

\section{Technology recommendations for patients}

Of the psychiatrists, $56.8 \%$ routinely recommend web sites to patients with bipolar disorder, with the types of web sites shown in Table 2-Q26. Many patients do not ask for a recommendation, with only $23.4 \%$ of respondents saying that more than half of patients ask for a recommendation. More psychiatrists practicing for at least 15 years said that at least half of the patients asked for a recommendation, than those in practice less than 15 years $(30 \%$ vs. $17 \%, \mathrm{p}=0.006)$. Of the psychiatrists that recommend web sites, $40.7 \%$ recommend sites about bipolar disorder, and $26.4 \%$ recommend government mental health sites.

The technology-based treatments that psychiatrists routinely recommend are shown in Table 2-Q27, although $60.0 \%$ of psychiatrists do not routinely recommend these. About half of the psychiatrists would consider the patient's technical competence before recommending technology-based treatments. Other reasons why psychiatrists hesitate to recommend technologybased treatments are shown in Table 2-Q29. Psychiatrists who do not communicate with patients using any 
Table 2 Psychiatrist responses to selected questions $(\mathrm{N}=\mathbf{2 0 9})$

\begin{tabular}{lll}
\hline Question N & Option
\end{tabular}

Q11 Do you routinely communicate with patients using any of these technologies? (Check all that apply)

$\begin{array}{lll}29 & 14 & \text { Secure email (encrypted) } \\ 102 & 49 & \text { Standard email } \\ 74 & 35 & \text { Text message } \\ 17 & 8 & \text { Social media } \\ 15 & 7 & \text { Patient portal on an EMR/EHR } \\ 74 & 35 & \text { None of the above }\end{array}$

Q12 What do you think are appropriate uses of email or online communication with patients? (Check all that apply)

$\begin{array}{lll}131 & 63 & \text { Notify if symptoms worse } \\ 105 & 50 & \text { Notify if new symptoms } \\ 73 & 35 & \text { Medication refills } \\ 55 & 26 & \text { Routine clinical follow-ups } \\ 63 & 30 & \text { New clinical questions } \\ 138 & 66 & \text { Lab test results } \\ 145 & 69 & \text { Administrative (appointments or billing) } \\ 12 & 6 & \text { None of the above } \\ 9 & 4 & \text { Other }\end{array}$

Q21 How would you describe the information that patients find online about bipolar disorder? (Check all that apply)

\begin{tabular}{|c|c|c|}
\hline 71 & 34 & Increased requests for a diagnosis of bipolar disorder \\
\hline 90 & 43 & Increased requests for specific medications \\
\hline 96 & 46 & $\begin{array}{l}\text { Increased requests for unnecessary medications or } \\
\text { tests }\end{array}$ \\
\hline 22 & 11 & Leads to delays in patients seeking help \\
\hline 26 & 12 & None of the above \\
\hline 27 & 13 & Don't know \\
\hline
\end{tabular}

Q22 Do you think that patient online information seeking is leading to any of these consequences? (Check all that apply)

$\begin{array}{lll}106 & 51 & \text { Improved discussions } \\ 56 & 27 & \text { Improved coping with the illness } \\ 31 & 15 & \text { Increased medication adherence } \\ 45 & 22 & \text { Increased patient confidence } \\ 103 & 49 & \text { Patients better able to express concerns } \\ 47 & 22 & \text { Few patients talk about information found online } \\ 14 & 7 & \text { None of the above } \\ 14 & 7 & \text { Don't know }\end{array}$

Q26 Do you routinely recommend any of these types of websites to patients with bipolar disorder? (Check all that apply)

\begin{tabular}{lll}
85 & 41 & Sites about mental health or bipolar disorder \\
18 & 9 & Sites about general medical information \\
14 & 7 & Sites about prescription drug information \\
45 & 22 & Government mental heath sites \\
12 & 6 & Government prescription drug sites \\
10 & 5 & Wikipedia \\
86 & 41 & Do not recommend websites \\
12 & 6 & Other \\
\hline
\end{tabular}


Table 2 (continued)

\begin{tabular}{|c|c|c|c|}
\hline Question & $\mathbf{N}$ & $\%$ & Option \\
\hline \multirow[t]{10}{*}{ Q27 } & \multicolumn{3}{|c|}{$\begin{array}{l}\text { What type of technology-based treatments (online, smartphone apps, or stand alone technologies) do you routinely recommend to } \\
\text { patients with bipolar disorder? (Check all that apply) }\end{array}$} \\
\hline & 8 & 4 & Online psychotherapy \\
\hline & 12 & 6 & Online patient support groups \\
\hline & 23 & 11 & Active patient monitoring \\
\hline & 13 & 6 & Passive patient monitoring \\
\hline & 34 & 16 & Sleep monitoring \\
\hline & 35 & 17 & Medication adherence support \\
\hline & 48 & 23 & Relaxation techniques \\
\hline & 123 & 59 & $\begin{array}{l}\text { Do not routinely recommend technology-based } \\
\text { treatments }\end{array}$ \\
\hline & 5 & 2 & Other \\
\hline \multirow[t]{9}{*}{ Q29 } & \multicolumn{3}{|c|}{ Do you hesitate in recommending technology-based treatments because of any of these reasons? (Check all that apply) } \\
\hline & 28 & 13 & Privacy considerations \\
\hline & 114 & 55 & Quality of information \\
\hline & 18 & 9 & Patient financial problems \\
\hline & 39 & 19 & Impact on patient behavior \\
\hline & 48 & 23 & Concern about online fraud \\
\hline & 17 & 8 & None of the above \\
\hline & 84 & 40 & $\begin{array}{l}\text { Do not routinely recommend technology-based } \\
\text { treatment }\end{array}$ \\
\hline & 7 & 3 & Other \\
\hline
\end{tabular}

new technologies such as email are less likely to recommend any technology-based treatments (22\% vs. 55\%, $\mathrm{p}=0.010)$. Of the psychiatrists, $66.3 \%$ think technologybased treatments will improve the quality of care for some or many patients, while $33.7 \%$ think it will rarely improve quality or do not know. Psychiatrists who routinely ask patients if they use the Internet in relation to bipolar disorder are more likely to believe that technology treatments will improve the quality of care $(80 \%$ vs. $59 \%, \mathrm{p}=0.011$ ). Only $23.9 \%$ of the psychiatrists provide information to patients on Internet privacy and security. Psychiatrists are more likely to provide information on Internet privacy and security when more than half of their patients have a mood disorder (32\% vs. 10\%; $\mathrm{p}=0.002$ ), and when they rate their technical competency as expert ( $44 \%$ vs. $18 \%, \mathrm{p}=0.011)$.

\section{Physician information seeking/value}

Virtually all psychiatrists (98.6\%) seek information on the Internet related to bipolar disorder: $72.7 \%$ seek information on drugs, $78.9 \%$ on drug interactions, $80.4 \%$ journal articles, $67.9 \%$ practice guidelines, $70.8 \%$ evidence based medicine reviews, and $24.4 \%$ information to tell patients. Males are more likely to seek journal articles online than females ( $89 \%$ vs. 67\%; $p=0.004)$. Almost all (95\%) find access to the vast online information is beneficial, with primary benefits including improved clinical decision making $(70.8 \%)$, increased confidence in decision making (58.9\%), improved patient safety (56.5\%), and improved diagnosis $(33.5 \%)$. Psychiatrists with patients living in urban areas are more likely to find online access leads to improved diagnosis than those with patients living in rural areas $(39 \%$ vs $14 \%, \mathrm{p}=0.005)$. Although $61.8 \%$ of psychiatrists find few or no negative consequences of access to so much information, $38.2 \%$ of psychiatrists find some negative consequences. These include errors from too much information (21.5\%), loss of focus from key issues (20.6\%), and a waste of time searching (13.4\%).

\section{Technology at work}

In this sample, $75.2 \%$ of psychiatrists use an EMR/EHR at work (including partial implementations), while $24.8 \%$ do not. More psychiatrists with patients living in urban areas use an EMR compared to those with patients living in suburban or rural areas $(78 \%$ vs $64 \%, \mathrm{p}=0.041)$. Of those who use an EMR, 36.1\% use only at work, $21.9 \%$ at work and at home, $20.6 \%$ at multiple work locations, and $21.3 \%$ at multiple work locations and at home. Of 
the psychiatrists, $66.5 \%$ never use telemedicine, $19.4 \%$ use $2-3$ times per year, $6.8 \%$ once a month, and $14.1 \%$ more frequently than monthly. Of the psychiatrists, about $66.7 \%$ email about patients to other healthcare providers, $42.6 \%$ to other physicians in their practice, $29.2 \%$ to physicians outside their practice, $8.6 \%$ to clinical laboratories, and 5.7\% to pharmacies. Of those who email about patients, about half use encrypted email, and half use standard email. For urgent clinical information, $45.4 \%$ prefer to be notified by providers using personal cellphone, $28.5 \%$ office phone, $10.6 \%$ email and $8.7 \%$ inperson. For routine clinical information, $46.9 \%$ prefer to be notified by email, $15.9 \%$ by office phone, $13.0 \%$ by personal cellphone, and $15.0 \%$ in-person.

\section{Technical knowledge/attitudes}

Virtually all psychiatrists (98.5\%) use technology devices at work including a desktop computer (74.2\%), smartphone $(60.3 \%)$, laptop $(56.9 \%)$, and tablet $(20.1 \%)$. Males are more likely to use a laptop than females (65\% vs. $44 \%$, $\mathrm{p}=0.012)$. The majority of psychiatrists $(74.8 \%)$ rate their overall technical competency as intermediate or lower, with $25.2 \%$ rating themselves as expert. Psychiatrists are more likely to rate themselves as expert when male (32\% vs. $15 \%, \mathrm{p}=0.015)$, and when they work in academic settings ( $34 \%$ vs. $17 \%, p=0.001)$. Only $23.9 \%$ of the respondents have had any formal training in computer science or information technology, unrelated to any demographic. Psychiatrists in practice for less than 15 years are more likely to say it is easy to learn new technology than those in practice for 15 or more years $(90 \%$ vs. $82 \%, p=0.035)$. Regarding the use of new technologies at work, most psychiatrists $(78.0 \%)$ are self-taught. Some psychiatrists also learn new technologies from technology staff at work (24.9\%), and from medical co-workers (20.6\%). Psychiatrists who were born in 1980 or later are more likely to learn from medical co-workers ( $28 \%$ vs. $14 \%, \mathrm{p}=0.034)$, and those working in academic settings are more likely to learn from technology staff at work ( $30 \%$ vs. $20 \%$, $\mathrm{p}=0.045)$.

\section{Discussion}

In this survey, virtually all psychiatrists used technology in routine clinical practice. There is near unanimous agreement about the benefits of access to the vast amount of information available online. Psychiatrists regularly go online to find journal articles, practice guidelines, drug prescribing information, and evidence based medicine reviews, and the benefits include improved clinical decision making, increased confidence in decision making, and improved patient safety. However, $38.2 \%$ of psychiatrists also reported negative consequences, including errors from too much information, a loss of focus and distraction from key issues, and wasting time. When information overload occurs, more information becomes a burden even if the new information is potentially useful (Bawden and Robinson 2009). Many clinical technologies can generate a large quantity of information for the physician to process and may contribute to information overload. These include data in EMR, alerts from clinical decision support systems, messages from clinicians and administrators, and data generated from patient smartphone apps and wearables (Sittig et al. 2016; Beasley et al. 2011; Bryant et al. 2014; Murphy et al. 2012; Singh et al. 2013).

In contrast to online information-seeking, there is much less agreement on the appropriate use and value of other technologies, especially when patients are directly involved. In this study, many differences are associated with the digital divide between patients who live in rural and urban areas, and the psychiatrist attitudes toward patient use of technology.

\section{Digital divide}

Psychiatrists are more likely to communicate with patients using new technologies and recommend technology-based treatments, when patients live in urban rather than rural or suburban areas. This is consistent with the digital divide (digital inequalities) that persists between urban and rural areas, even in highly digitalized societies in Europe and the US (Perrin 2019; Warf 2019). Access to fast broadband services from home is often unavailable in rural areas of the US, although access to cellular networks has increased (Perrin 2019; GreenbergWorisek et al. 2019). However, the digital divide extends beyond general Internet access to include inequalities in access to new mobile and Internet of Things (IOT) devices, Internet skills and literacy, ability to afford the ongoing maintenance costs of devices, software and subscriptions, and recognition of online fraud (van Deursen and van Dijk 2019; Lutz 2019). Patients in rural areas use technology less often to find health information than those in urban areas (Greenberg et al. 2018; Rains 2008).

In this survey, more psychiatrists use an EMR at work when patients live in urban rather than rural areas $(78 \%$ vs $64 \%$ ). In prior research, hospitals and ambulatory care practices in rural areas often lag in the implementation of advanced EMR functions compared to urban areas (Adler-Milstein et al. 2017; Kim et al. 2017; RumballSmith et al. 2018).

\section{Psychiatrist attitudes towards patient use of technology}

About $2 / 3$ of the psychiatrists in this survey do not ask their patients if they use the Internet to seek information on bipolar disorder. This is consistent with a prior survey of 976 patients with bipolar disorder who use 
the Internet, where about $2 / 3$ of patients rarely or never discussed information learned online with their doctor (Conell et al. 2016). The psychiatrists in this survey vary in their attitude towards patient use of technology. About $2 / 3$ of psychiatrists feel it is too early to tell if patient online information seeking about bipolar disorder is improving the quality of care. When psychiatrists believe that patients who discuss information found online are more informed, they are more likely to ask patients if they seek information online. If psychiatrists do ask patients about Internet use, it is more likely that at least half will discuss their findings, and that patients will request a treatment found online. Psychiatrists should be ready to respond to patient questions about technology, even if they do not recommend it. Since most psychiatrists in this survey find some inaccuracies in what patients read online about bipolar disorder, they may want to suggest reliable online sources of information (Monteith et al. 2013).

Although $2 / 3$ of the psychiatrists think technologybased treatments will improve the quality of care for some or many patients, $60 \%$ of psychiatrists do not routinely recommend technology-based treatments for many reasons including the quality of information. The psychiatrists who routinely ask patients if they use the Internet in relation to bipolar disorder are more likely to believe that technology-based treatments will improve the quality of care. Psychiatrists who do not communicate with patients using any type of new technology are less likely to recommend technology-based treatments. Of those who do recommend technology-based treatments, there is variety in what is recommended.

\section{Psychiatrist technology training}

As shown in this survey, a variety of technology is routinely used in the clinical practice of psychiatry, and new applications are available daily. Yet less than a quarter of the psychiatrists have any formal training in technology, unrelated to demographics. Of technologies at work, 78\% of the psychiatrists are self-taught users. There is concern that many psychiatrists may not have the background to understand the complex issues of modern technology.

Psychiatrists need an informed framework to evaluate claims for technology products aimed at physicians and patients. This is increasingly important for several reasons: (1) Many new products are based on technologies that psychiatrists may have no clear understanding of, such as AI. (2) There is an atmosphere of constant tech hype to encourage use of new technology by vendors, venture capitalists, entrepreneurs, technology analysts, and university public relations, which is further amplified by social media and sponsored content appearing as technology news across the web (Funk 2019). (3)
The limited regulatory requirements for many technology products may not provide the expected assurance of safety and efficacy (Lee and Kesselheim 2018; Parker et al. 2019). (4) Psychiatrists and patients will be interacting with technologies in diverse ways, often previously unimagined.

Psychiatrists need to understand the risks, benefits, and limitations of technology products (Bauer et al. 2020, 2019; Monteith and Glenn 2019; Monteith et al. 2016), to purchase or recommend products from vendors who provide algorithm transparency (IEEE 2019; ACM 2018), and to understand standard security practices to protect themselves and their patients. Importantly, psychiatrists should understand the limitations of their knowledge and skills, when to ask for assistance, and how to select and hire competent technology and cybersecurity consultants.

\section{Limitations}

There are many limitations to this study. The response rate was relatively low, as often reported for online-only surveys of physicians (Sebo et al. 2017; Weaver et al. 2019, Cunningham et al. 2015). Self-reported surveys on timely topics may be subject to response bias, as psychiatrists who are technology enthusiasts may be more likely to have completed the survey. This population may not be generalizable to other psychiatrists. With many younger psychiatrists completing the survey, the results are not well suited for analysis of age-related impacts. The survey did not investigate the features, usability, or efficacy of any specific product such as an EMR or patient smartphone app (Melnick et al. 2019, Bauer et al. 2020). The many challenges associated with automating clinical psychiatry, such as the impacts on physician workflow, multitasking, automation complacency and bias, data quality and algorithm bias, and patient stigma were not discussed (Bauer et al. 2017, 2019). Many studies cited, such as on the use of EMR, were from general medicine rather than psychiatry.

The surveys were completed and this paper submitted before the 2020 pandemic and subsequent increase in technology use in routine medical care. This rapid expansion exacerbated problems such as the digital divide (Renault 2020; Kim et al. 2020), security risks for patients, physicians and medical centers (FBI 2020; Bergal 2020), and inadequately tested apps (Anderson 2020; Leprince-Ringuet 2020). Corrective steps are complex and vary with the specific technology and the healthcare and legal systems in a country. 


\section{Conclusions}

In conclusion, psychiatrists routinely use digital technology in clinical practice. There is near unanimous agreement about the benefits of online information-seeking for psychiatrists. Some psychiatrists also report negative effects due to information overload, which needs further investigation. There is less agreement about the appropriate use of other clinical technologies, especially those involving patients. Most psychiatrists think it is too early to tell if patient Internet activities will improve the quality of care, and that technology-based treatments may improve the quality of care for some patients. However, most psychiatrists do not currently recommend technology-based treatments. The digital divide remains between use of technology for psychiatrists with patients living in urban and rural areas. Psychiatrists should be prepared to answer patient questions related to technology. Psychiatrists need more technology training to understand the risks, benefits, and limitations of technology products.

\section{Supplementary information}

Supplementary information accompanies this paper at https://doi. org/10.1186/s40345-020-00194-1.

\section{Additional file 1. MD survey.}

Additional file 2. Collaborators.

\section{Acknowledgements}

We thank Saskia Melzig for administrative support for this project. We thank the working group members who recommended contacts to complete the survey, shown in Additional file 2. We acknowledge support by the Open Access Publication Funds of the SLUB/TU Dresden.

\section{Authors' contributions}

RB and TG completed the initial draft, which was reviewed by all authors. All authors read and approved the final manuscript.

\section{Funding}

Open access funding provided by Projekt DEAL.

\section{Availability of data and materials}

The data will not be shared or made publicly available.

\section{Ethics approval and consent to participate}

Not applicable.

\section{Consent for publication}

The authors provide consent for publication.

\section{Competing interests}

All authors have no conflict of interest to declare.

\section{Author details}

1 Department of Psychiatry and Psychotherapy, University Hospital Carl Gustav Carus Medical Faculty, Technische Universität Dresden, Dresden, Germany. ${ }^{2}$ ChronoRecord Association, Fullerton, CA, USA. ${ }^{3}$ Michigan State University College of Human Medicine, Traverse City Campus, Traverse City, MI, USA. ${ }^{4}$ Department of Psychiatry and Biobehavioral Sciences, Semel Institute for Neuroscience and Human Behavior, University of California Los Angeles (UCLA), Los Angeles, CA, USA.
Received: 18 February 2020 Accepted: 16 July 2020

Published online: 03 October 2020

\section{References}

ACM. ACM Code of ethics and professional conduct. Section 2.5. 2018. https:// www.acm.org/code-of-ethics\#h-2.5-give-comprehensive-and-thoroughevaluations-of-computer-systems-and-their-impacts,-including-analy sis-of-possible-risks. Accessed 22 Jan 2020.

Adler-Milstein J, Holmgren AJ, Kralovec P, Worzala C, Searcy T, Patel V. Electronic health record adoption in US hospitals: the emergence of a digital "advanced use" divide. J Am Med Inform Assoc. 2017;24:1142-8.

Anderson R. Contact tracing in the real world. Light Blue Touchpaper, University of Cambridge. Apr 12,2020. https://www.lightbluetouchpaper. org/2020/04/12/contact-tracing-in-the-real-world/ Accessed 29 June 2020.

Bauer R, Conell J, Glenn T, Alda M, Ardau R, Baune BT, et al. Internet use by patients with bipolar disorder: results from an international multisite survey. Psychiatry Res. 2016;242:388-94.

Bauer M, Glenn T, Monteith S, Bauer R, Whybrow PC, Geddes J. Ethical perspectives on recommending digital technology for patients with mental illness. Int J Bipolar Disord. 2017;5:6.

Bauer M, Monteith S, Geddes J, Gitlin MJ, Grof P, Whybrow PC, et al. Automation to optimise physician treatment of individual patients: examples in psychiatry. Lancet Psychiatry. 2019;6:338-49.

Bauer M, Glenn T, Geddes J, Gitlin M, Grof P, Kessing LV, et al. Smartphones in mental health: a critical review of background issues, current status and future concerns. Int J Bipolar Disord. 2020;8:2.

Bawden D, Robinson L. The dark side of information: overload, anxiety and other paradoxes and pathologies. J Inf Sci. 2009;35:180-91.

Beasley JW, Wetterneck TB, Temte J, Lapin JA, Smith P, Rivera-Rodriguez AJ, et al. Information chaos in primary care: implications for physician performance and patient safety. J Am Board Fam Med. 2011;24:745-51.

Bergal J. Hospital hackers seize upon coronavirus pandemic. Pew Research. April 13, 2020. https://www.pewtrusts.org/en/research-and-analysis/ blogs/stateline/2020/04/13/hospital-hackers-seize-upon-coronaviru s-pandemic. Accessed 29 Jun 2020.

Berwick DM, Nolan TW, Whittington J. The triple aim: care, health, and cost. Health Aff (Millwood). 2008;27:759-69.

Bhugra D, Tasman A, Pathare S, Priebe S, Smith S, Torous J, et al. The WPA-Lancet Psychiatry Commission on the Future of Psychiatry. Lancet Psychiatry. 2017:4:775-818.

Bryant AD, Fletcher GS, Payne TH. Drug interaction alert override rates in the Meaningful Use era: no evidence of progress. Appl Clin Inform. 2014;5:802-13.

Conell J, Bauer R, Glenn T, Alda M, Ardau R, Baune BT, et al. Online information seeking by patients with bipolar disorder: results from an international multisite survey. Int J Bipolar Disord. 2016;4:17.

Cunningham CT, Quan H, Hemmelgarn B, Noseworthy T, Beck CA, Dixon E, et al. Exploring physician specialist response rates to web-based surveys. BMC Med Res Methodol. 2015;15:32.

FBI. Cyber actors take advantage of COVID-19 pandemic to exploit increased use of virtual environments. 2020. https://www.ic3.gov/media /2020/200401.aspx. Accessed 29 June 2020.

Funk Jeffrey. What's behind technological hype? Issues Sci Technol. 2019;36:36-42.

Greenberg AJ, Haney D, Blake KD, Moser RP, Hesse BW. Differences in access to and use of electronic personal health information between rural and urban residents in the United States. J Rural Health. 2018;34(Suppl 1):s30-8.

Greenberg-Worisek AJ, Kurani S, Finney Rutten LJ, Blake KD, Moser RP, Hesse BW. Tracking healthy people 2020 Internet, broadband, and mobile device access goals: an update using data from the Health Information National Trends Survey. J Med Internet Res. 2019;21:e13300.

IEEE. The IEEE global initiative on ethics of autonomous and intelligent systems. general principles. EAD1E. Sept 9, 2019. https://standards.ieee. org/industry-connections/ec/autonomous-systems.html. Accessed 22 Jan 2020.

Kim J., Desai E, Cole MB. How The Rapid Shift To Telehealth Leaves Many Community Health Centers Behind During The COVID-19 Pandemic, "Health 
Affairs Blog, June 2, 2020. ttps://www.healthaffairs.org/do/10.1377/hblog 20200529.449762/full/. Accessed 22 Jan 2020.

Kim J, Ohsfeldt RL, Gamm LD, Radcliff TA, Jiang L. Hospital characteristics are associated with readiness to attain Stage 2 Meaningful Use of electronic health records. J Rural Health. 2017;33:275-83.

Lee TT, Kesselheim AS. U.S. Food and Drug Administration precertification pilot program for digital health software: weighing the benefits and risks. Ann Intern Med. 2018;168:730-2.

Leprince-Ringuet D. Contact-tracing app: How much difference will it really make. ZDNet. May 29, 2020. https://www.zdnet.com/article/contact-traci ng-app-how-much-difference-will-it-really-make/. Accessed 29 June 2020.

LimeSurvey https://www.limesurvey.org/ 2019. Accessed 22 Jan 2020.

Lutz C. Digital inequalities in the age of artificial intelligence and big data. Hum Behav Emerg Technol. 2019;1 (2):141-8.

Melnick ER, Dyrbye LN, Sinsky CA, Trockel M, West CP, Nedelec L, et al. The association between perceived electronic health record usability and professional burnout among US Physicians. Mayo Clin Proc. 2019. https:// doi.org/10.1016/..mayocp.2019.09.024.

Monteith S, Glenn T. A comparison of potential psychiatric drug interactions from six drug interaction database programs. Psychiatry Res. 2019;275:366-72.

Monteith S, Glenn T, Bauer M. Searching the Internet for health information about bipolar disorder:some cautionary issues. Int J Bipolar Disord. 2013;1:22.

Monteith S, Glenn T, Geddes J, Whybrow PC, Bauer M. Big data for bipolar disorder. Int J Bipolar Disord. 2016;4:1.

Murphy DR, Reis B, Kadiyala H, Hirani K, Sittig DF, Khan MM, et al. Electronic health record-based messages to primary care providers: valuable information or just noise? Arch Intern Med. 2012;172:283-5.

Parker L, Bero L, Gillies D, Raven M, Grundy Q. The, "Hot Potato" of mental health app regulation: a critical case study of the Australian policy arena. Int J Health Policy Manag. 2019;8:168-76.
Perrin A. Digital gap between rural and nonrural America persists. Pew Research. May 31, 2019. https://www.pewresearch.org/facttank/2019/05/31/digital-gap-between-rural-and-nonrural-america-persi sts/. Accessed 22 Jan 2020.

Rains SA. Health at high speed: broadband Internet access, health communication, and the digital divide. Commun Res. 2008;35:283-97.

Renault M. When Health Care Moves Online, Many Patients Are Left Behind. Wired. 6/8/2020. https://www.wired.com/story/health-care-online-patie nts-left-behind/. Accessed 29 June 2020.

Rumball-Smith J, Shekelle P, Damberg CL. Electronic health record "superusers" and "under-users" in ambulatory care practices. Am J Manag Care. 2018;24:26-31

Sebo P, Maisonneuve H, Cerutti B, Fournier JP, Senn N, Haller DM. Rates, delays, and completeness of general practitioners'responses to a postal versus web-based survey: a randomized trial. J Med Internet Res. 2017;19:e83.

Singh H, Spitzmueller C, Petersen NJ, Sawhney MK, Sittig DF. Information overload and missed test results in electronic health record-based settings. JAMA Intern Med. 2013;173:702-4.

Sittig DF, Wright A, Ash J, Singh H. New unintended adverse consequences of electronic health records. Yearb Med Inform. 2016; 7-12.

van Deursen AJ, van Dijk JA. The first-level digital divide shifts from inequalities in physical access to inequalities in material access. New Media Soc. 2019;21:354-75.

Warf B. Teaching digital divides. J Geog. 2019;118:77-87.

Weaver L, Beebe TJ, Rockwood T. The impact of survey mode on the response rate in a survey of the factors that influence Minnesota physicians' disclosure practices. BMC Med Res Methodol. 2019;19:73.

\section{Publisher's Note}

Springer Nature remains neutral with regard to jurisdictional claims in published maps and institutional affiliations.

\section{Submit your manuscript to a SpringerOpen ${ }^{\circ}$ journal and benefit from:}

- Convenient online submission

- Rigorous peer review

- Open access: articles freely available online

- High visibility within the field

- Retaining the copyright to your article

Submit your next manuscript at $\boldsymbol{\nabla}$ springeropen.com 